\title{
Correction to: Copper Bioaccumulation Kinetics in Swan Mussel, Anodonta cygnea (Linnaeus, 1758) During Waterborne Exposure to CuO Nanoparticles
}

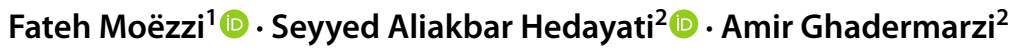

Accepted: 30 December 2020 / Published online: 18 January 2021

(c) Springer Science+Business Media, LLC, part of Springer Nature 2021

\section{Correction to: \\ Bulletin of Environmental Contamination and Toxicology (2019) 102:46-51 \\ https://doi.org/10.1007/s00128-018-2489-z}

The original version of this article unfortunately contained a typo in university name in second affiliation. The correct affiliation is Department of Aquatic Production and Exploitation, Faculty of Fisheries and Environmental Sciences, Gorgan University of Agricultural Sciences and Natural Resource, Gorgan, Iran.
Publisher's Note Springer Nature remains neutral with regard to jurisdictional claims in published maps and institutional affiliations.

The original article can be found online at https://doi.org/10.1007/ s00128-018-2489-z.

Fateh Moëzzi

fmoezi.fateh@gmail.com

1 Department of Fisheries, Faculty of Natural Resources,

University of Tehran, Karaj, Iran

2 Department of Aquatic Production and Exploitation, Faculty of Fisheries and Environmental Sciences, Gorgan University of Agricultural Sciences and Natural Resource, Gorgan, Iran 